\title{
Enhanced Atlantic freshwater export during El Niño
}

\author{
Andreas Schmittner, Christof Appenzeller and Thomas F. Stocker \\ Climate and Environmental Physics, Physics Institute, University of Bern, Switzerland
}

\begin{abstract}
Using two reanalysis data sets, the influence of El Niño/Southern Oscillation (ENSO) on the surface freshwater balance of the Atlantic ocean is examined. We present evidence that the transport of water vapour out of the tropical Atlantic is enhanced during warm ENSO phases, while it is reduced during cold phases. These tropical changes alter the freshwater budget of the entire Atlantic drainage basin. The difference in freshwater export between La Niña and El Niño years is on the order of $0.1 \mathrm{~Sv}\left(1 \mathrm{~Sv}=10^{6} \mathrm{~m}^{3} \mathrm{~s}^{-1}\right)$ for the entire Atlantic. Results from an idealized coupled ocean-atmosphere model suggest that this amplitude is of significance for the strength of the North Atlantic thermohaline ocean circulation, if the persistence of the anomaly is on the order of decades.
\end{abstract}

\section{Introduction}

The Atlantic thermohaline circulation (THC) and its associated heat transport has a profound impact on the North Atlantic and European climate. Paleoclimatic indications for THC variability [e.g. Bond et al., 1993] prompted the question if such changes could occur in the future, e.g. as a response to anthropogenic warming. Coupled oceanatmosphere models of different complexities showed qualitatively similar behaviour [e.g. Manabe and Stouffer, 1993; Stocker and Schmittner, 1997]. In most models a substantial reduction in strength of the THC was simulated due to warming and freshening of the surface waters in the North Atlantic. A notable exception is a recent simulation in which the THC is only sightly affected by global warming [Latif and Roeckner, 2000]. In a warmer climate their model shows a transition towards permanent El Niño conditions [Timmermann et al., 1999]. This increases the freshwater export from the Atlantic to the other ocean basins and provides a stabilising effect on the THC.

It is well known that the net surface freshwater balance of the Atlantic is negative [Baumgartner and Reichel, 1975] due to an export of water vapour through the atmosphere [Weyl, 1968]. The stability of the THC strongly depends on the amount of this freshwater export [Zaucker et al., 1994]. However, the relation between ENSO, the strongest signal of natural interannual climate variability, and the net freshwater balance of the Atlantic has not been examined in detail. Here two reanalysis datasets are used to explore this relationship quantitatively, and the results are applied to an idealised climate model in order to test its impact for the North Atlantic THC.

Copyright 2000 by the American Geophysical Union.

Paper number 1999GL011048. 0094-8276/00/1999GL011048\$05.00

\section{Data sets}

Evaporation (E) and precipitation $(\mathrm{P})$ rates calculated from a reanalysis forecast system provide one possibility to overcome the otherwise sparse observational network. The analysis is based on data from the National Center for Environmental Prediction (NCEP) [Kalnay et al., 1996] as well as from the European Center for Medium Range Weather Forecast (ECMWF) [Gibson et al., 1997]. The data consist of monthly fields from the 39-year period from 1958 to 1996 (NCEP) and from 1979 to 1994 (ECMWF reanalysis; ERA henceforth), respectively. The horizontal resolution is $2.5^{\circ} \times 2.5^{\circ}(\mathrm{NCEP})$ and approximately $1.1^{\circ} \times 1.1^{\circ}(\mathrm{ERA})$.

There are several known problems with the derived evaporation and precipitation fields. Trenberth and Guillemot [1998] report that interannual variability in tropical precipitation seems to be underestimated by the NCEP reanalysis, whereas the ERA seems to overestimate the tropical precipitation [Stendel and Arpe, 1997]. In addition, the freshwater balance is not strictly closed in a global sense and the calculated imbalances show interannual variability which is larger in the ERA than in the NCEP reanalysis [Schmittner et al., 2000]. The analysis presented is therefore based on both, the original and corrected (by subtracting the global imbalance of E-P) data. Overall the results show no significant differences, except where explicitly stated, and the figures presented are based on the uncorrected data.

\section{ENSO control on Atlantic E-P}

Figure 1 shows the spatial pattern of the influence of ENSO on the surface freshwater flux in the mid and low latitude Atlantic drainage basin from the NCEP reanalysis. Changes in the precipitation pattern dominate the freshwater flux anomalies, while evaporation differences are of secondary importance. The signal is strongest at the east coast of south America and over tropical Africa, where the freshwater flux into the Atlantic basin is increased during positive phases of the SOI (La Niña conditions). The increased freshwater flux into the Atlantic basin there is partly compensated by decreased precipitation elsewhere (e.g. in central Brazil south of the Amazon estuary, in mid latitudes over south eastern North America and the open Atlantic). These results are consistent with local observations [Rao et al., 1995] and other studies of the tropical Atlantic freshwater budget [Yoo and Carton, 1990]. Results qualitatively similar to Fig. 1 can be obtained from the ERA data. They are not shown here because significance is largely reduced in the shorter ERA.

In Fig. 2 time series of the tropical Atlantic freshwater balance together with the SOI are shown. Both NCEP and ERA reanalysis suggest a clear anti-correlation between the two quantities. The linear correlation coefficient is -0.64 $(-0.52)$ for the NCEP (ERA) reanalysis. During phases of positive SOI values, which correspond to La Niña events, less 


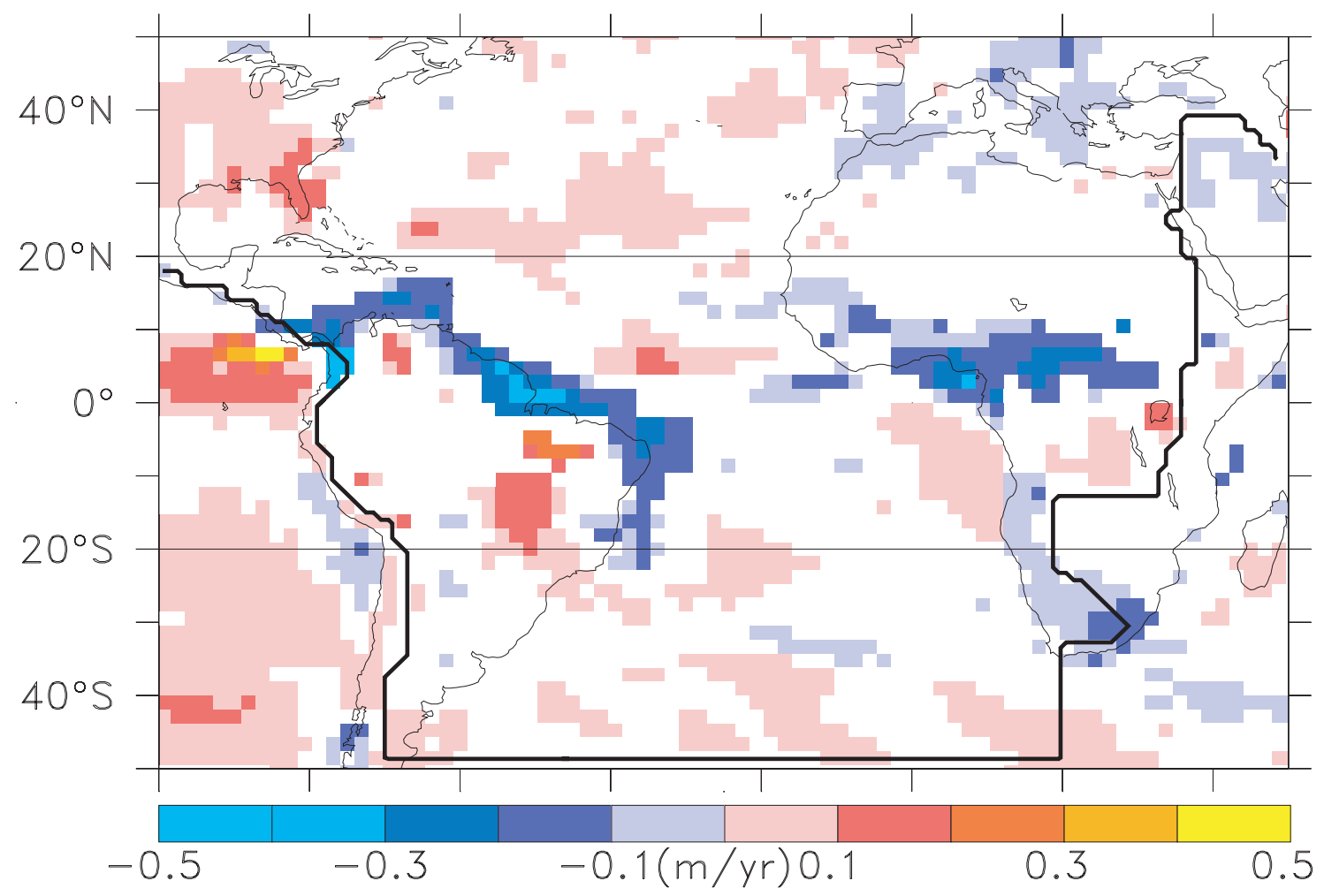

Figure 1. Spatial distribution of the surface freshwater flux (E-P) anomalies in the mid and low latitude Atlantic drainage basin due to changes in the Southern Oscillation Index (SOI) by one. The SOI is defined as the sea level pressure difference between Darwin and Tahiti divided by its standard deviation. At each grid point of the NCEP data a linear regression of the 39-yr E-P time series with the SOI time series is carried out. Plotted is the slope of the regression line. The original monthly data are smoothed with a 12 month sliding window and values are only shown if the correlation coefficients exceed \pm 0.24 , which corresponds to the $95 \%$ confidence level. The drainage basin of the Atlantic ocean is indicated by the thick black line and the thin lines mark the tropical belt from $20^{\circ} \mathrm{S}$ to $20^{\circ} \mathrm{N}$.

freshwater is exported from the tropical Atlantic, whereas the loss of water vapour is increased during El Niño years. It can also be seen from Fig. 2 that the agreement between the two reanalyses is not perfect. But the sign of the anomalies and the general pattern is mostly consistent. The 1982/83 El Niño, for example, has a similar imprint in both data sets. ERA shows somewhat larger amplitudes than the NCEP reanalysis, but this difference could be an artifact of the imbalances discussed above. If we subtract the global mean, the amplitudes of the ERA data are in better agreement with the NCEP reanalysis, although still larger, while the
NCEP fluxes do not change much. The correlation coefficient given above increases to -0.68 for the corrected ERA data, whereas it remains nearly the same for the NCEP reanalysis $(-0.65)$.

Figure 3 shows the correlation coefficients for the tropical as well as for the total Atlantic freshwater export with the SOI as a function of the averaging time. The correlation between the tropical freshwater balance in the Atlantic is clearly above the $99 \%$ significance level for all averaging periods. However, it increases considerably if monthly to intra-seasonal variability is suppressed, and has its largest

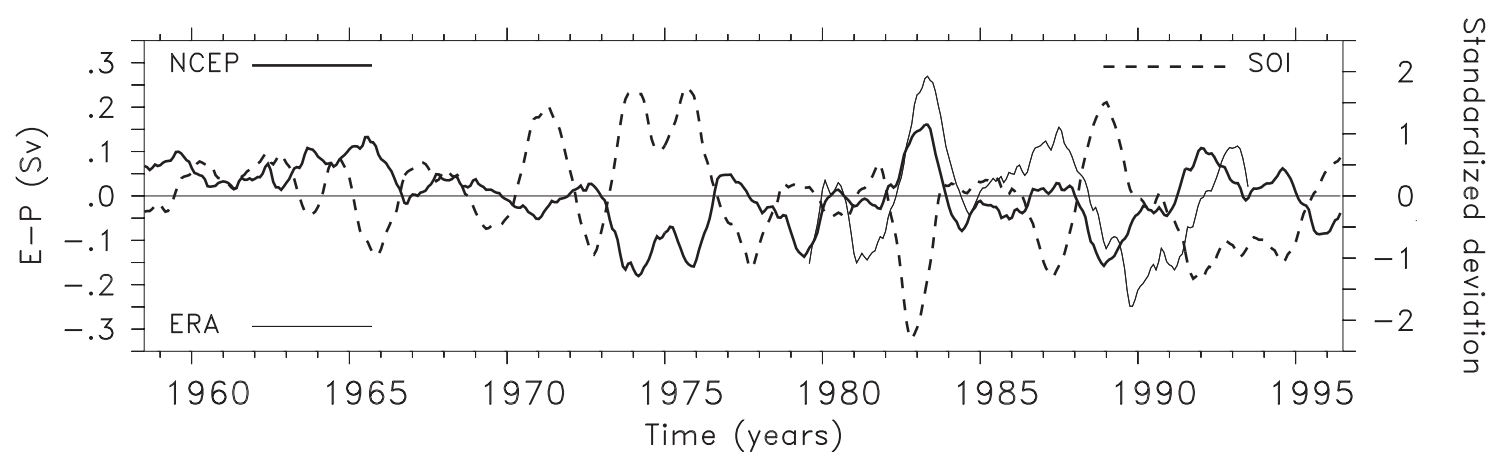

Figure 2. Time series of the SOI (dashed line, right axis) and the freshwater flux anomaly (E-P) of the tropical Atlantic (solid lines, left axis) in Sverdrups $\left(1 \mathrm{~Sv}=10^{6} \mathrm{~m}^{3} \mathrm{~s}^{-1}\right)$. The E-P anomalies have been integrated over the Atlantic drainage basin from $20^{\circ} \mathrm{S}$ to $20^{\circ} \mathrm{N}$. The mean seasonal cycle is removed from the monthly data and a low pass filter is applied using a 12 month sliding window. 


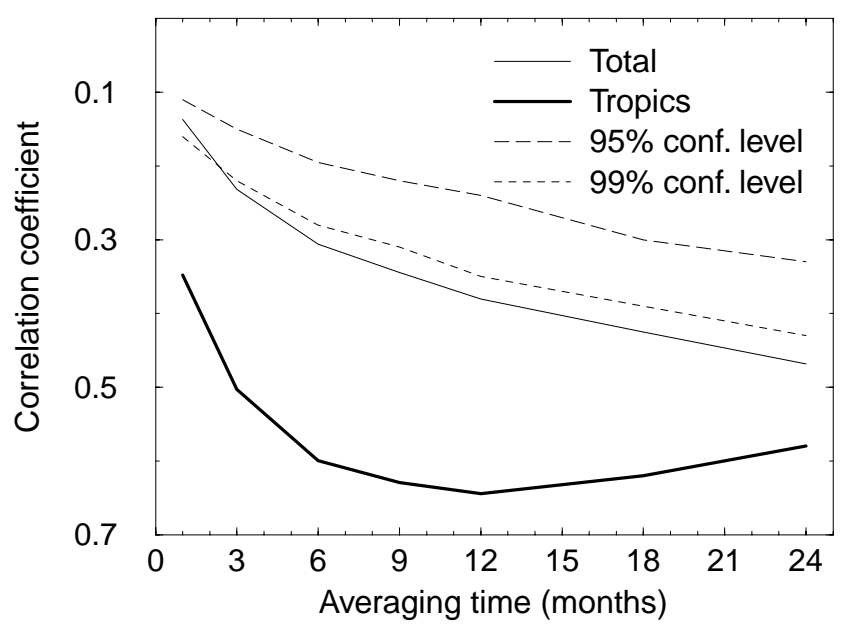

Figure 3. Correlation coefficient between the freshwater balance of the tropical Atlantic (NCEP) and the SOI (thick solid line) as a function of the length of the averaging time window. The correlation for the entire Atlantic basin is also shown (thin solid line). The mean seasonal cycle is removed and $99 \%$ and $95 \%$ confidence levels are indicated by the dashed lines. These result from Monte-Carlo simulations in which 1000 random time series have been computed with the same autocorrelation as the original monthly data ( 0.783 for the SOI and 0.462 for E-P) and using the same averaging procedure.

absolute values for averaging periods around one year. If the extra-tropics are also considered, the correlation with the SOI decreases but is still above the $99 \%$ confidence level for averaging periods longer than three months. For the total Atlantic drainage basin the significance for averaging periods of one year or longer should be taken with some caution because the probability density distributions are becoming less Gaussian. This effect is smaller for the tropical Atlantic.

The amplitude of the changed tropical Atlantic freshwater export between $20^{\circ} \mathrm{S}$ and $20^{\circ} \mathrm{N}$ has been estimated by a linear regression to be $-0.06 \mathrm{~Sv}$ (NCEP) for an increase of the Southern Oscillation Index by one unit $(-0.08 \mathrm{~Sv}$ for ERA). By calculating the correlation coefficients for $10^{\circ}$ latitude bands, we found that about $0.01 \mathrm{~Sv}$ (NCEP) is transported meridionally from the tropical Atlantic into the belt between $20^{\circ} \mathrm{N}$ and $30^{\circ} \mathrm{N}(0.02 \mathrm{~Sv}$ for ERA). The rest is exchanged in the zonal direction since no significant correlations were found in the other parts of the extra-tropical Atlantic. In these large-scale features both reanalyses agree quite well, while locally the differences are larger. These findings are consistent with correlations between observed low level winds and ENSO [Enfield and Mayer, 1997].

\section{Effect on the thermohaline circulation}

The net freshwater balance of the Atlantic influences the density of the ocean surface waters which in turn is affecting the strength of the THC [e.g. Mikolajewicz and MaierReimer, 1994]. Our analysis suggests that one standard deviation in SOI alters the Atlantic freshwater balance by -0.05 to $-0.06 \mathrm{~Sv}$. This amplitude may have little effect on the stability of the North Atlantic thermohaline circulation if El Niño and La Niña years alter with similar frequencies, since it is likely that the equatorial freshwater anomalies are diluted during their advection to the northern North
Atlantic regions of deep water formation. If the coupled atmosphere-ocean system remained in a phase of ENSO for a time span similar to, or longer than the advective timescale for surface waters to reach the northern North Atlantic, then the deep water formation might be significantly disturbed. In order to test this hypothesis we use a low-order, coupled ocean-atmosphere model which consists of a zonally averaged, 4-basin, latitude-depth ocean component [Wright et al., 1992] coupled to an energy-moisture balance model of the atmosphere [Stocker and Schmittner, 1997] including the seasonal cycle. Note that the model cannot simulate ENSO; rather we force it by exchanging freshwater between the tropical Atlantic and Pacific. This freshwater forcing is applied with different amplitudes and for periods ranging from one year to 100 years.

In Fig. 4 results from these sensitivity experiments are shown. In steady state the model produces about $23 \mathrm{~Sv}$ NADW. As expected the Atlantic overturning reduces (strengthens) for decreased (increased) freshwater export out of the Atlantic. The response of the THC is larger for longer persistence of the perturbation. For a disturbance comparable in amplitude to todays ENSO variability $(0.1 \mathrm{~Sv} \hat{=} 2 \sigma$ change in SOI) the Atlantic overturning slightly changes as the persistence time increases and equilibrates for periods longer than about 50 years at $10-20 \%$ difference. For the present model, a freshwater perturbation $(0.2 \mathrm{~Sv})$ equivalent to strong $(4 \sigma)$ La Niña conditions lasting longer than 70 years would lead to a collapse of the THC. This is an indication that changes in the tropics could trigger rapid climate variations in the high latitudes of the Atlantic. The threshold value for a permanent perturbation is between $0.1 \mathrm{~Sv}$ and $0.2 \mathrm{~Sv}$. Our results suggest rather extreme perturbations to trigger a THC collapse (4 to $8 \sigma$ SOI changes), but this, of course, is highly model-dependent.

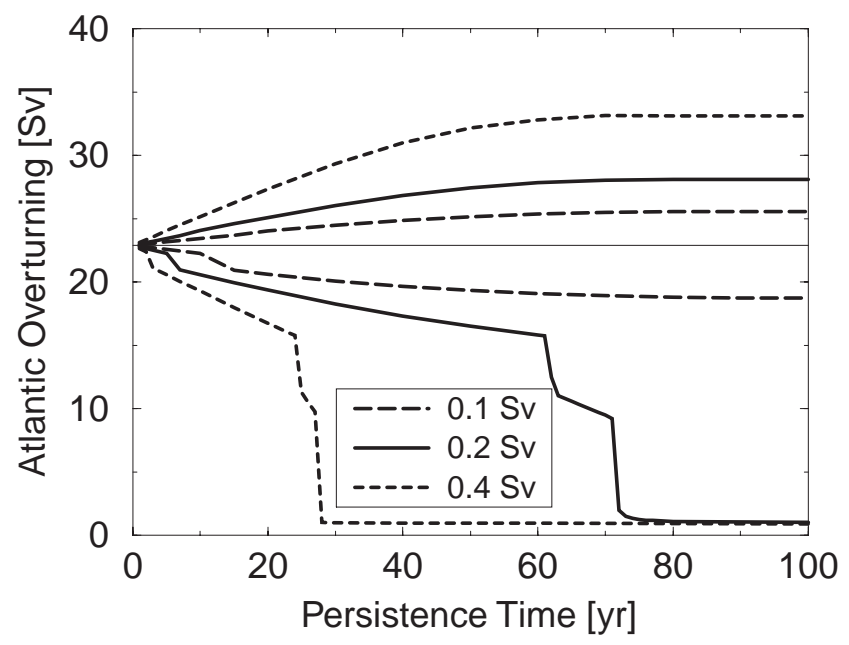

Figure 4. Modelled maximum change in North Atlantic deep water formation rate as response to tropical freshwater perturbations as a function of the persistence time of the perturbations. Freshwater is exchanged between the tropical Atlantic and Pacific between $20^{\circ} \mathrm{S}$ and $20^{\circ} \mathrm{N}$ at three different rates $(0.1 \mathrm{~Sv}, 0.2 \mathrm{~Sv}$ and $0.4 \mathrm{~Sv}$ ). Upper lines correspond to a transfer of freshwater from the Atlantic to the Pacific, representing increased El Niño frequencies. Lower lines result from additional freshwater transport from the Pacific to the Atlantic, representing La Niña years. The thin line indicates the unperturbed overturning. 
Present-day decadal variability of the Atlantic freshwater balance due to changes of the SOI is much smaller than the interannual variability and thus no significant influence of tropical Pacific sea surface temperature changes on the North Atlantic thermohaline circulation is to be expected. In a changed climate, however, the mean state of the climate system can be shifted into a more El Niño or a more La Niña-like state. Such changes have been found in recent paleo-simulations with a tropical Pacific model [Clement et $a l ., 1999]$ and in a global warming simulation with a coupled ocean-atmosphere model [Timmermann et al., 1999]. There exist also paleoclimatic indications that ENSO was in a more La Niña-like state during the Last Glacial Maximum [Mix et al., 1999]. Therefore, our results suggest that the relation between ENSO, the Atlantic freshwater budget and the THC should be considered as a potentially important physical mechanism linking tropical and high-latitude climate in the discussion of past and future climate changes.

Acknowledgments. Monthly SOI values and NCEP reanalysis data have been provided through the NOAA Climate Diagnostics Center (http://www.cdc.noaa.gov/). ERA data have been provided by the European Center for Medium Range Weather Forecast. This work was supported by the Swiss National Science Foundation.

\section{References}

Baumgartner, A., and E. Reichel, The World Water Balance, 179 pp., Elsevier, 1975.

Bond, G., W. S. Broecker, S. J. Johnsen, J. McManus, L. Labeyrie, J. Jouzel, and G. Bonani, Correlations between climate records from North Atlantic sediments and Greenland ice, Nature, 365, 143-147, 1993.

Clement, A. C., R. Seager, and Cane, M. A., Orbital controls on the El Niño/Southern Oscillation and the tropical climate, Paleoceanogr., 14, 441-456, 1999.

Enfield, D. B., and D. A. Mayer, Tropical Atlantic sea surface temperature variability and its relation to El Niño-Southern Oscillation, J. Geophys. Res., 3, 929-945, 1997.

Gibson, J. K., P. Kållberg, S. Uppala, A. Nomura, A. Hernandez, E. Serrano, and J. K. Gibson, ERA description, in ECMWF Re-Analysis Project Report Series, Volume 1. ECMWF, Reading, UK, 1997.

Kalnay, E., M. Kanamitsu, R. Kistler, D. W., et al., The NCEP/NCAR 40 year reanalysis project, Bull. Amer. Meteorol. Soc., 77, 437-471, 1996.

Latif, M., and E. Roeckner, Tropical stabilisation of the thermohaline circulation in a greenhouse warming simulation, $J$. Clim., 2000, in press.
Manabe, S., and R. J. Stouffer, Century-scale effects of increased atmospheric $\mathrm{CO}_{2}$ on the ocean-atmosphere system, Nature, $364,215-218,1993$.

Mikolajewicz, U., and E. Maier-Reimer, Mixed boundary conditions in ocean general circulation models and their influence on the stability of the model's conveyor belt, J. Geophys. Res., 99, 22633-22644, 1994.

Mix, A. C., A. Morey, N. G. Pisias, and S. Hostetler, Foraminiferal faunal estimates of paleotemperature: Circumventing the no-analog problem yields cool ice age tropics, $\mathrm{Pa}$ leoceanogr., 14, 350-359, 1999.

Rao, V. B., M. C. De Lima, and S. H. Franchito, Seasonal and interannual variations of rainfall over eastern Northeast Brazil, J. Clim., 25, 787-805, 1995.

Schmittner, A., C. Appenzeller, and T. F. Stocker, Validation of parameterisations for the meridional energy and moisture transport used in simple climate models, Climate Dyn., 16, 63-77, 2000.

Stendel, M., and K. Arpe, Evaluation of the hydrological cylce in reanalyses and observations, Rep. No. 228, Max-PlanckInstitut für Meteorologie, Hamburg, Germany, 1997.

Stocker, T. F., and A. Schmittner, Influence of $\mathrm{CO}_{2}$ emission rates on the stability of the thermohaline circulation, Nature, 388, 862-865, 1997.

Trenberth, K. E., and C. J. Guillemot, Evaluation of the atmospheric moisture and hydrological cycle in the NCEP/NCAR reanalyses, Climate Dyn., 14, 213-231, 1998.

Timmermann, A., J. Oberhuber, A. Bacher, M. Esch, M. Latif, and E. Roeckner, Increased El Niño frequency in a climate model forced by future greenhouse warming, Nature, 398, 694696, 1999.

Weyl, P. K., The role of the oceans in climatic change: a theory of the ice ages, Meteorol. Monogr., 8, 37-62, 1968.

Wright, D. G., and T. F. Stocker, Sensitivities of a zonally averaged global ocean circulation model, J. Geophys. Res., 97, 12707-12730, 1992

Yoo, J.-M., and J. A. Carton, Annual and interannual variation of the freshwater budget in the tropical Atlantic ocean and the Caribbean Sea, J. Phys. Oceanogr., 20, 831-845, 1990.

Zaucker, F., T. F. Stocker, and W. S. Broecker, Observed and modeled freshwater fluxes and their effect on the global thermohaline circulation, J. Geophys. Res., 99, 12443-12457, 1994.

A. Schmittner, School of Earth and Ocean Sciences, University Victoria, PO Box 3055, Stn CSC, Victoria V8W 3P6, Canada; C. Appenzeller, Swiss Meteorological Institute, Zürich, Switzerland; and T. F. Stocker, Climate and Environmental Physics, University of Bern, Bern, Switzerland. (email: andreas@ocean.seos.uvic.ca)

(Received September 14, 1999; accepted January 18, 2000) 